Buletin Ilmiah Math. Stat. dan Terapannya (Bimaster)

Volume 08, No. 3 (2019), hal 447 - 452.

\title{
JUMLAH BINTANG PADA GRAF BUNGA MATAHARI
}

\author{
Putra Yudha Pranata, Mariatul Kiftiah, Fransiskus Fran
}

\begin{abstract}
INTISARI
Graf bunga merupakan graf yang termasuk keluarga graf cycle dan memiliki pola berbentuk seperti bunga. Sebagai contoh yaitu graf bunga matahari yang dinotasikan dengan $S F_{n}$ merupakan keluarga graf cycle. Pada penelitian ini akan membahas tentang jumlah bintang pada graf bunga matahari. Jumlah bintang yang dinotasikan dengan $s(G)$ adalah istilah yang digunakan untuk menyatakan jumlah minimum partisi bintang dalam sebuah graf $G$. Partisi bintang didefinisikan sebagai satu atau lebih graf bintang, yaitu graf dengan satu simpul pusat yang bersisian ke simpul lainnya. Graf bunga matahari pada penelitian ini dibangun oleh beberapa graf pembangun yaitu graf yang menjadi dasar terbentuknya graf bunga matahari. Graf pembangun tersebut diantaranya graf lintasan non trivial, graf cycle, graf lengkap, graf bipartisi lengkap, dan graf roda. Penelitian dimulai dengan menganalisis jumlah bintang pada graf pembangun, selanjutnya menganalisis jumlah bintang pada graf bunga matahari dengan meninjau jumlah bintang pada graf pembangun. Jumlah bintang yang diperoleh untuk graf bunga matahari adalah, $s\left(S F_{n}\right)=n$.
\end{abstract}

Kata Kunci : jumlah bintang, graf bintang, graf bunga matahari

\section{PENDAHULUAN}

Graf bunga merupakan graf yang termasuk keluarga graf cycle dan memiliki pola berbentuk seperti bunga. Penelitian ini fokus graf bunga matahari. Graf bunga matahari merupakan graf roda yang memiliki satu simpul tambahan pada setiap sisinya, dan setiap simpul tambahan tersebut bersisian dengan 2 simpul pada sisi graf roda.. Graf bunga matahari dibentuk dari beberapa graf pembangun yaitu, graf lintasan non trivial, graf cycle, graf lengkap, graf bipartisi lengkap, dan graf roda.

Terdapat beberapa topik pembahasan dalam teori graf, salah satunya adalah pembahasan untuk mencari jumlah bintang pada suatu graf. Secara umum jumlah bintang adalah banyaknya partisi bintang atau beberapa graf bintang yang dapat membangun suatu graf tertentu. Jumlah bintang pada suatu graf yang pertama kali diperkenalkan oleh Kulli dan Sigarkanti pada tahun 1992. Kulli dan Sigarkanti memperkenalkan jumlah bintang sebagai jumlah minimum partisi bintang yang terkandung dalam sebuah graf. Penelitian selanjutnya tentang jumlah bintang dibahas oleh Bhavanari dan Devanaboina pada tahun 2016. Penelitian tersebut memiliki fokus pembahasan mengenai beberapa graf sederhana yang membentuk suatu graf baru.

Graf bintang secara umum adalah graf yang memiliki satu simpul pusat yang bersisian ke simpul lainnya. Graf bintang juga merupakan kasus khusus dari graf bipartisi lengkap. Graf bipartisi lengkap yang dinotasikan dengan $K_{m, n}$, yaitu suatu graf dengan himpunan partisi $V_{1}$ dan $V_{2}$ dengan $\left|V_{1}\right|=m$ dan $\left|V_{2}\right|=n$, sehingga untuk $m=1\left(K_{1, n}\right)$ merupakan sebuah graf bintang [1].

Pembahasan jumlah bintang dalam suatu graf memiliki tujuan untuk mengetahui jumlah minimum partisi bintang dalam suatu graf. Jumlah minimum partisi bintang dapat digunakan dalam masalah optimasi penyebaran informasi, contohnya dalam penyelesaian masalah optimasi siaran pesan pada sistem jaringan pengiriman pesan [2].

Pengembangan materi dalam kasus menentukan jumlah bintang merupakan topik yang menarik untuk dikaji. Penelitian ini akan membahas pembentukan formula jumlah bintang pada graf bunga matahari. penelitian dimulai dengan mengkaji literatur mengenai teori graf secara umum dan berlanjut pada fokus teori yaitu jumlah bintang dalam suatu graf. Tahap berikutnya adalah membentuk dan membuktikan formula untuk mencari jumlah bintang pada graf pembangun. Formula yang telah diperoleh kemudian digunakan untuk membentuk formula jumlah bintang pada graf bunga matahari. Proses untuk membangun formula jumlah bintang pada graf bunga matahari dimulai dengan mencari 
secara manual partisi bintang minimum dengan meninjau derajat simpul tertinggi untuk mendapatkan pola jumlah bintang, Kemudian dari pola yang diperoleh dirumuskan formula jumlah bintang untuk graf yang dianalisis. Langkah terakhir adalah melakukan pembuktian terhadap formula yang diperoleh.

\section{JUMLAH BINTANG}

Jumlah bintang dalam suatu graf dihitung berdasarkan jumlah graf bintang yang membangun graf tersebut. Graf bintang adalah graf yang memiliki satu simpul sebagai pusat bintang dan memiliki minimal satu simpul lainnya yang bertetangga ke pusat bintang. Berikut diberikan definisi dari graf bintang.

Definisi 1 [3] Suatu graf $G=(V, E)$ dikatakan graf bintang jika terdapat simpul $v$ (pusat dari graf bintang) sedemikian sehingga $E=\{(v, u) \mid u \in V$ dan $u \neq v\}$. Graf bintang disimbolkan dengan $S_{n}$ dengan jumlah simpul dari graf adalah $n+1$ dan satu simpul sebagai pusat bintang.

Jumlah bintang yang dinotasikan dengan $s(G)$ dari suatu graf $G$ adalah jumlah minimum subset dari himpunan sisi pada $G$ yang dapat dipartisi sehingga, setiap subset dapat membentuk graf bintang [4]. Partisi bintang dalam kasus ini adalah himpunan graf bintang yang termuat dalam sebuah graf. Berikut diberikan definisi partisi secara umum dan definisi partisi bintang.

Definisi 2 [5] Himpunan bagian $A_{1}, A_{2}, \ldots, A_{k}$ dari A dikatakan partisi dari A atau mempartisi $A$ jika

a. $A=A_{1} \cup A_{2} \cup \ldots \cup A_{k}$,

b. $A_{i} \cap A_{j}=\emptyset$ untuk $i \neq j$.

Definisi 3 [6] Andaikan terdapat $P B=\left\{P B_{1}, P B_{2}, P B_{3}, \ldots, P B_{k}\right\}$ di sebuah graf $G$. $P B$ disebut partisi bintang jika setiap kelas-kelas partisi $P B_{i}, 1 \leq i \leq k$ membentuk sebuah graf bintang di graf $G$ dan semua respresentasi dari setiap simpul $v \in V(G)$ berbeda.

Contoh 1 Diberikan graf $G$ dengan 5 simpul dan 5 sisi seperti yang di visualisasikan pada Gambar 1 .

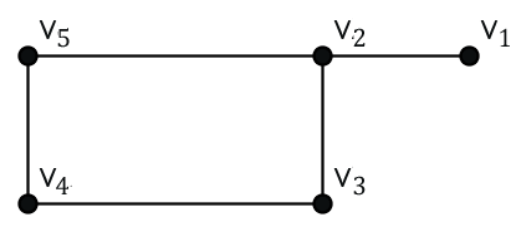

\section{Gambar 1 Contoh Graf $G$}

Graf $G$ dapat dipartisi menjadi beberapa graf bintang. Berdasarkan derajat simpul tertinggi dapat ditentukan jumlah minimum partisi bintang pada graf $G$ adalah 2 dengan pusat masing-masing partisi yaitu $v_{2}$ dan $v_{4}$. Berikut diberikan visualisasi partisi bintang pada graf $G$.

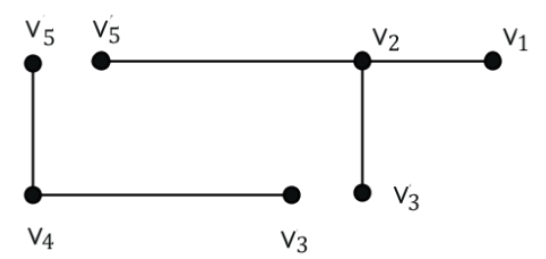




\section{Jumlah Bintang Graf Pembangun}

Graf bunga matahari dibentuk dari beberapa graf pembangun yaitu graf lintasan non trivial, graf cycle, graf bipartisi lengkap, graf lengkap, dan graf roda. Langkah awal untuk mengetahui jumlah bintang pada pada graf tersebut perlu dianalisis jumlah bintang pada tiap-tiap graf pembangun. Berikut diberikan visualisasi dari graf pembangun.

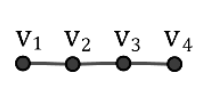

(a)

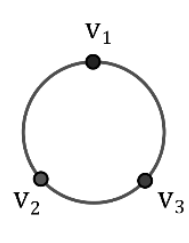

(b)

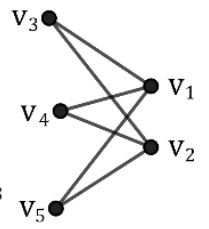

(c)

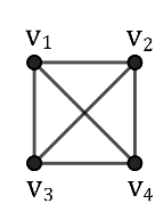

(d)

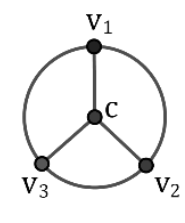

(e)

Gambar 3 (a) Graf Lintasan Nontrivial $P_{4}$, (b) Graf Cycle $C_{3}$, (c) Graf Bipartisi Lengkap $K_{2,3}$, (d) Graf Lengkap $K_{4}$, dan (e) Graf Roda $W_{3}$

Selanjutnya yaitu jumlah bintang dari 5 graf pembangun yang dijelaskan pada proposisi dan observasi berikut.

Proposisi 1 [4] Untuk sebuah graf lintasan non trivial $P_{n}$ dengan $n$ simpul maka jumlah bintang yang terkandung dalam graf $P_{n}$ yaitu, $s\left(P_{n}\right)=\left\lfloor\frac{n}{2}\right\rfloor$.

Contoh 2 Diberikan graf lintasan non trivial $P_{4}$ yang divisualisasikan pada Gambar 3 (a). Berdasarkan Proposisi 1, jumlah bintang untuk $P_{4}$ yaitu, $s\left(P_{4}\right)=\left\lfloor\frac{4}{2}\right\rfloor=2$. Berikut diberikan contoh visualisasi partisi bintang minimum pada $P_{4}$.
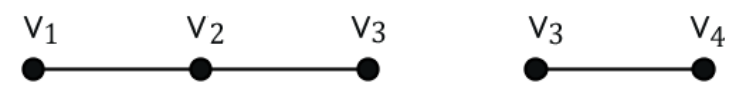

\section{Gambar 4 Partisi Bintang Minimum Graf $P_{4}$}

Proposisi 2 [4] Untuk graf cycle $C_{n}$ dengan n simpul maka jumlah bintang yang termuat dalam graf $C_{n}$ yaitu, $s\left(C_{n}\right)=\left\lceil\frac{n}{2}\right\rceil$.

Contoh 3 Diberikan graf cycle $C_{3}$ yang divisualisasikan pada Gambar 3 (b). Berdasarkan Proposisi 2, jumlah bintang untuk $C_{3}$ yaitu, $s\left(C_{3}\right)=\left\lceil\frac{3}{2}\right\rceil=2$. Berikut diberikan contoh visualisasi partisi bintang minimum pada $C_{3}$.
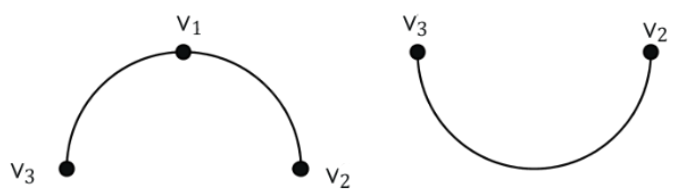

Gambar 5 Partisi Bintang Minimum pada $C_{3}$ 
Proposisi 3 [4] Untuk graf lengkap $K_{n}$ dengan $n \geq 2$, jumlah bintang yang terkandung dalam $K_{n}$ yaitu $s\left(K_{n}\right)=n-1$.

Contoh 4 Diberikan graf lengkap $K_{4}$ yang divisualisasikan pada Gambar 3 (d). Berdasarkan Proposisi 3 , jumlah bintang untuk $K_{4}$ yaitu, $s\left(K_{4}\right)=4-1=3$. Berikut diberikan contoh visualisasi partisi bintang minimum pada $K_{4}$.
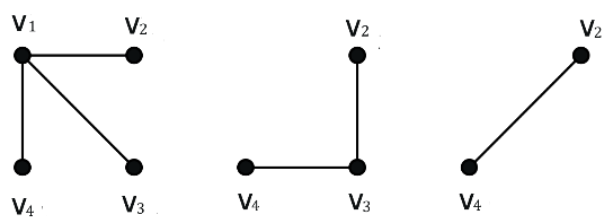

\section{Gambar 6 Partisi Bintang Minimum pada $K_{4}$}

Proposisi 4 [4] Untuk sebuah graf bipartisi lengkap $K_{m, n}, 1 \leq m \leq n$, jumlah bintang yang terkandung dalam $K_{m, n}$ adalah $s\left(K_{m, n}\right)=m$.

Contoh 5 Diberikan graf bipartisi lengkap $K_{2,3}$ yang divisualisasikan pada Gambar 3 (c). Berdasarkan Proposisi 4, jumlah bintang untuk $K_{2,3}$ yaitu, $s\left(K_{2,3}\right)=2$. Berikut diberikan contoh visualisasi partisi bintang minimum pada $K_{2,3}$.

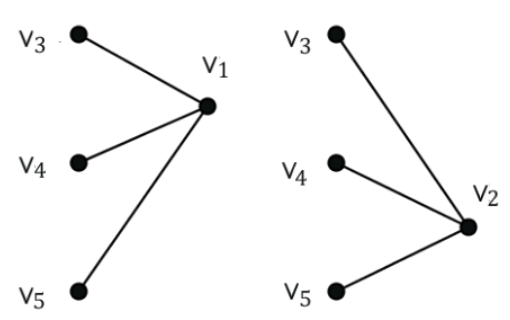

\section{Gambar 7 Partisi Bintang Minimum pada $K_{2,3}$}

Observasi 1 Untuk sebuah graf roda $W_{n}$ yang berorder $n$, jumlah bintang yang terkandung dalam $W_{n}$ yaitu, $s\left(W_{n}\right)=1+\left\lceil\frac{n}{2}\right\rceil$.

Bukti: Diketahui graf roda $W_{n}$ dibentuk dari sebuah graf bintang $S_{n}$ sedemikian sehingga, pasti ada 1 graf bintang yang memuat semua simpul di $W_{n}$. Berdasarkan definisi graf roda, diketahui terdapat $n$ simpul dalam graf roda yang membentuk graf $C_{n}$. Berdasarkan Proposisi 2, maka diperoleh:

$$
s\left(W_{n}\right) \leq s\left(K_{1, n}\right)+s\left(C_{n}\right)=1+\left\lceil\frac{n}{2}\right\rceil
$$

sehingga, $s\left(W_{n}\right) \leq 1+\left\lceil\frac{n}{2}\right\rceil$

Selanjutnya akan ditunjukan $s\left(W_{n}\right)=1+\left\lceil\frac{n}{2}\right\rceil$, andaikan $s\left(W_{n}\right)=\left(1+\left\lceil\frac{n}{2}\right\rceil\right)-1$, artinya ada $\left\lceil\frac{n}{2}\right\rceil$ partisi bintang yang dapat membentuk $W_{n}$. Berdasarkan Proposisi 2, $\left\lceil\frac{n}{2}\right\rceil$ merupakan jumlah bintang dari graf $C_{n}$ yang tidak memenuhi definisi graf $W_{n}$. Jadi diperoleh kontradiksi sehingga dapat ditentukan jumlah partisi bintang minimum atau jumlah bintang dari suatu graf roda $s\left(W_{n}\right)=1+\left\lceil\frac{n}{2}\right\rceil$ 
Contoh 6 Diberikan graf roda $W_{3}$ yang divisualisasikan pada Gambar 3 (e). Berdasarkan Observasi 1 , jumlah bintang untuk $W_{3}$ yaitu, $s\left(W_{3}\right)=1+\left\lceil\frac{3}{2}\right\rceil=3$. Berikut diberikan contoh visualisasi partisi bintang minimum pada $W_{3}$.

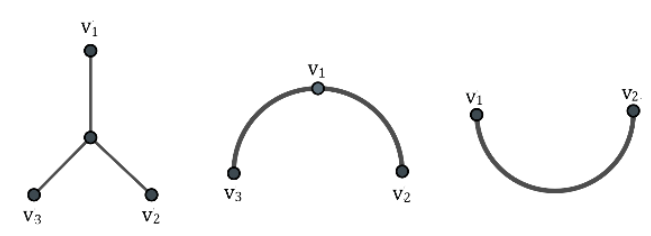

\section{Gambar 8 Partisi Bintang Minimum pada $W_{3}$}

\section{Jumlah Bintang Graf Bunga Matahari $S F_{n}$}

Graf bunga matahari atau biasa disebut graf sunflower yang dinotasikan dengan $S F_{n}$ adalah suatu graf yang serupa dengan graf roda. Perbedaan yang dimiliki graf bunga matahari dengan graf roda yaitu, graf bunga matahari memiliki simpul tambahan yang bertetangga dengan dua simpul pada graf roda untuk masing-masing simpul tambahan. Berikut adalah definisi dari graf bunga matahari.

Definisi 4 [7] Graf bunga matahari diperoleh dari graf roda dengan simpul pusat c dengan cycle berorder $n$, simpul $v_{1}, v_{2}, v_{3}, \ldots, v_{n}$ dan $n$ simpul tambahan $w_{1}, w_{2}, w_{3}, \ldots, w_{n}$, selanjutnya $w_{i}$ yang dihubungkan dengan simpul ke $v_{i}, v_{i-1}$ untuk $i=1,2,3 \ldots, n$.

Graf bunga matahari $S F_{n}$ memiliki jumlah simpul $2 n+1$ dan jumlah sisi $4 n$. Berikut dalam Gambar 4 contoh visualisasi graf bunga matahari $S F_{n}$.

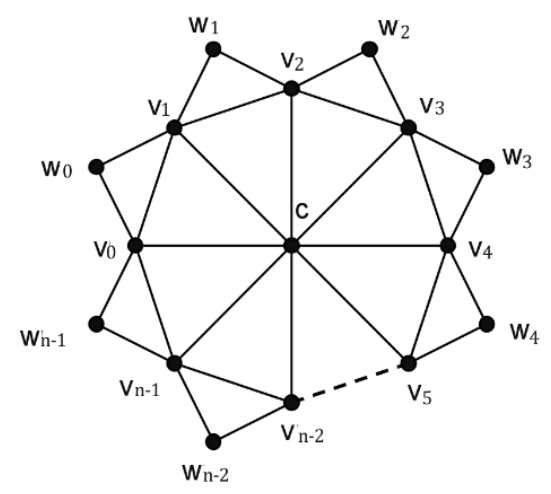

\section{Gambar 9 Graf Bunga Matahari $S F_{n}$}

Observasi 2 Untuk sebuah graf bunga matahari $S F_{n}$ yang berorder $n$, jumlah bintang yang terkandung dalam $S F_{n}$ yaitu:

$$
s\left(S F_{n}\right)=n
$$

Bukti: Berdasarkan definisi graf bunga matahari, diketahui graf $S F_{n}$ terbentuk dari graf roda dan terdapat $m$ simpul tambahan. Karena masing-masing simpul tambahan bertetangga ke $v_{i}, v_{i+1}$ untuk $i=1,2, \ldots, n$ dan masing-masing simpul $v_{i}$ juga bertetangga ke pusat $c$, maka diperoleh $n$ buah partisi bintang yang berpusat di $v_{i}$ yang memuat semua sisi di $S F_{n}$. Akibatnya simpul $v_{i}$ memiliki derajat simpul tertinggi untuk semua $i$, sedemikian sehingga diperoleh: 


$$
s\left(S F_{n}\right) \leq n
$$

Selanjutnya akan ditunjukan $s\left(S F_{n}\right)=n$. Andaikan $s\left(W_{n}\right)=(n)-1$, Artinya ada $n-1$ partisi bintang yang dapat membentuk $S F_{n}$. Berdasarkan Proposisi 3, $n-1$ merupakan jumlah bintang graf $K_{n}$ yang tidak memenuhi definisi graf $S F_{n}$. Sehingga diperoleh kontradiksi dan dapat ditentukan jumlah partisi bintang minimum atau jumlah bintang dari suatu graf bunga matahari $s\left(S F_{n}\right)=n \boldsymbol{\square}$.

Contoh 7 Diberikan graf bunga matahari $S F_{5}$. Berdasarkan Observasi 2, jumlah bintang untuk $S F_{5}$ yaitu, $s\left(S F_{5}\right)=5$. Berikut diberikan contoh visualisasi partisi bintang minimum pada $S F_{5}$.
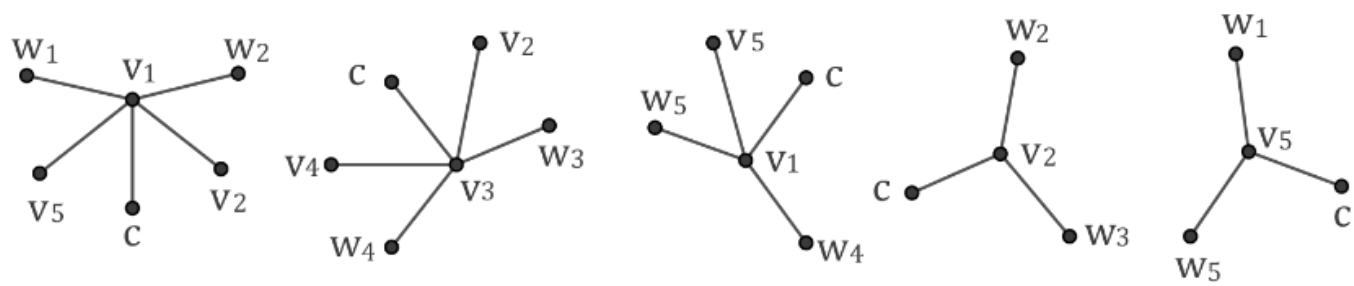

\section{Gambar 10 Partisi Bintang Minimum pada $S_{F_{5}}$}

\section{PENUTUP}

Proses untuk membentuk formula jumlah bintang, langkah awal adalah menganalisis pola jumlah bintang pada graf pembangun dan graf bunga matahari. Kemudian dari pola yang diperoleh, dibentuk formula bintang pada graf bunga matahari dengan meninjau formula bintang graf pembangun. Sehingga didapatkan formula bintang graf bunga matahari yaitu, $s\left(S F_{n}\right)=n$.

\section{DAFTAR PUSTAKA}

[1] Chartrand G, Lesniak L. Graphs and Digraphs. Third Edition. California: Wadsworth Inc; 1996

[2] Fragopoulou P, Akl SG. Optimal Communication Algorithms on Star Graphs Using Spanning Tree Constructions. Journal of Parallel and Distributed Computing. 1995; 24: 55-71.

[3] Bhavanari S, Devanaboina S, Bhavanari M. Star Number of A Graph. Research Journal of Science and IT Management. 2016; 5(11): 18-22.

[4] Kulli VR, Sigarkanti SC. On The Tree and Star Numbers of A Graph. Journal of Computer and Mathematical Science. 2015; 6(1): 25-32.

[5] Munir, R. 2010. Matematika Diskrit. Edisi 3. Pustaka Informatika. Bandung.

[6] Alfarisi R. Dimensi Partisi dan Dimensi Partisi Bintang Graf Hasil Operasi Comb Dua Graf Terhubung. [Tesis]. Surabaya: Institusi Teknologi Sepuluh November; 2017

[7] Javaid I, Shokat S. On The Partition Dimension of Some Wheel Related Graphs. Journal of Prime Research in Mathematics. 2008; 4: 154-164.

PUTRA YUDHA PRANATA : Jurusan Matematika FMIPA UNTAN, Pontianak putrayudhapranata@gmail.com

MARIATUL KIFTIAH

: Jurusan Matematika FMIPA UNTAN, Pontianak kiftiahmariatul@math.untan.ac.id

FRANSISKUS FRAN : Jurusan Matematika FMIPA UNTAN, Pontianak frandly88@gmail.com 